American Journal of Environmental Sciences 6 (1): 71-77, 2010

ISSN 1553-345X

(C) 2010 Science Publications

\title{
Coconut Oil Based Hybrid Fuels as Alternative Fuel for Diesel Engines
}

\author{
${ }^{1}$ Pranil Singh, ${ }^{2}$ Jagjit Khurma and ${ }^{1}$ Anirudh Singh \\ ${ }^{1}$ Division of Physics, School of Engineering and Physics, \\ Faculty of Science, Technology and Environment, \\ University of the South Pacific, Suva, Fiji \\ ${ }^{2}$ Division of Chemistry, Faculty of Science, School of Biological and Chemical Sciences, \\ Technology and Environment, University of the South Pacific, Suva, Fiji
}

\begin{abstract}
Problem statement: The use of vegetable oils as a fuel in diesel engines causes some problems due to their high viscosity compared with diesel. Various techniques and methods are used to solve the problems resulting from high viscosity. Approach: One of the techniques is the preparation of a microemulsion fuel, called a hybrid fuel. In this study, hybrid fuels consisting of coconut oil, ethanol and octan-1-ol were prepared with an aim to test their suitability as a fuel for diesel engines. Density, viscosity and gross calorific values of these fuels were determined and the fuels were used to run a direct injection diesel engine. The engine performance and exhaust emissions were investigated and compared with that of diesel and coconut oil. Results: The experimental results show that the engine efficiency of the hybrid fuels is comparable to that of diesel. As the percentage of ethanol and/or octan-1-ol increased, the viscosity of the hybrid fuels decreased and the engine efficiency increased. The exhaust emissions were lower than those for diesel, except carbon monoxide, which increased. Conclusion/Recommendations: Hence, it is concluded that these hybrid fuels can be used successfully as an alternative fuel in diesel engines without any modifications. Their completely renewable nature ensures that they are environmentally friendly.
\end{abstract}

Key words: Diesel engine, coconut oil, hybrid fuel, engine performance, emission

\section{INTRODUCTION}

The indiscriminate extraction and lavish consumption of fossil fuels have led to reduction in underground petroleum resources. With the exception of hydroelectricity and nuclear energy, the majority of the worlds energy needs are supplied through petrochemical sources (Machacon et al., 2001). The depletion of world petroleum reserves and increased environmental concerns has stimulated recent interest in sources alternative to petroleum-based fuels. Biofuels produced using various production techniques have become potential candidates for diesel substitute due to the similarities of their properties.

Vegetable oils as fuel for diesel engines have become attractive recently because of the fact that they are made from renewable resources. However, direct use of vegetable oils for both direct and indirect injection type diesel engines is unsatisfactory due to their high viscosities and low volatilities (Rakopoulos et al., 2006; Nwafor, 2004; Demirbas, 2006).
The high viscosity of vegetable oil interferes with the injection process and leads to poor fuel atomization. The inefficient mixing of fuel with air contributes to incomplete combustion. Oxidative and thermal polymerization of vegetable oils causes a deposition on the injectors forming a film that continues to trap fuel and interfere with combustion. The long term operation of engine using vegetable oils normally results in deposit formation, carbonization of injector tips, ring sticking, lubrication oil thickening, gelling and degradation, cold engine start up, misfire and ignition delay (Demirbas, 2008; Srivastava and Prasad, 2000). It is therefore unsuitable to use pure vegetable oils in diesel engines.

To overcome these problems, a number of techniques have been employed. These include dilution or blending of vegetable oils with diesel, increasing the fuel temperature, pyrolysis, transesterification to produce biodiesel and microemulsification to make hybrid fuels (Puhan and Nagarajan, 2008).

Corresponding Author: Pranil Singh, Division of Physics, School of Engineering and Physics, Faculty of Science, Technology and Environment, University of the South Pacific, 325 Fletcher Road, Vatuwaqa, Suva, Fiji Tel: (679) 3232822 Fax: (679) 3231511 
The hybrid fuels investigated in this study are microemulsions consisting of vegetable oil, ethanol and octan-1-ol which act as a surfactant. The surfactant increases the solubility of vegetable oil and ethanol by lowering the interfacial tension between them so that a stable homogenous mixture consisting of a single phase is obtained (Pryde, 1984). The surfactant orientates itself in such a way that the hydrophilic end is oriented towards water and the hydrophobic end is oriented towards the oil

The objectives of this study were to prepare ethanol and coconut oil based fuels using the microemulsification technique and to determine their relevant properties, engine performance and exhaust emission characteristics. The chemical and physical properties of the fuels were investigated. The results of the engine performance and the emission characteristics of a direct injection diesel genset operated on these blends are reported.

\section{MATERIALS AND METHODS}

Ethanol (95\%) and octan-1-ol were obtained from Unilab Chemicals, Ajax Finechem, Australia. Two types of coconut oil, Crude Coconut Oil (CCO) extracted from copra using the traditional method (Copra Millers, Savusavu, Fiji) and Virgin Coconut Oil (VCO) extracted using the direct micro expelling method (Organic Pacific Limited, Suva, Fiji) were used. All the materials were used without further purification.

The effect of addition of octan-1-ol on the miscibility of coconut oil and ethanol was studied by titration method. Mixtures of coconut oil and ethanol were made in which the ethanol percentage was varied from $0-20 \%$ by volume in $2 \%$ increments and then from $20-100 \%$ by volume in $10 \%$ increments. Mixtures with more that $8 \%$ ethanol turned milky and eventually separated into two phases in a few minutes. The surfactant octan-1-ol was then added to the mixture until the mixture became clear. The samples were kept for a period of 7 days to ascertain the stability through physical appearance, after which the data were used to construct the phase diagrams. All samples were kept at room temperature for a further period of six months to observe the long term stability. Six homogeneous and stable hybrid fuels, designated from HF1-HF6, were tested during the present study. The compositions of these fuels are given in Table 2.

The relative density of the hybrid fuels, coconut oils (CCO and VCO) and diesel was measured using $50 \mathrm{~mL}$ pycnometer at $26^{\circ} \mathrm{C}$. An Ostwald viscometer was used to measure the kinematic viscosities at $26^{\circ} \mathrm{C}$ and $20^{\circ} \mathrm{C}$. A Gallenkamp ballistic bomb calorimeter was used to measure the gross calorific value. The densities, kinematic viscosities and gross calorific values of the hybrid fuels and its individual constituents are given in Table 2.

The efficiency tests were performed on a PowerTec 170FG, four-stroke, single cylinder, air-cooled, direct injection diesel engine. The specifications of the engine are given in Table 1. A modified fuel tank, consisting of two separate measuring cylinders was used. One contained the diesel, while the other was for the hybrid fuels. The engine was started with diesel and then switched to the hybrid fuel. The engine was coupled to an electrical generator through which load was applied.

\begin{tabular}{ll} 
Table 1: Technical specifications of the test engine \\
\hline Item & Specification \\
\hline Model & PowerTec 170FG \\
Injection type & Direct injection \\
Maximum output & $3.8 \mathrm{hp}$ \\
Continuous output & $3.4 \mathrm{hp}$ \\
Bore & $70 \mathrm{~mm}$ \\
Stroke & $55 \mathrm{~mm}$ \\
Displacement & $0.211 \mathrm{~L}$ \\
Cooling system & Forced air-cooled system \\
Lubricating system & Forced lubrication \\
\hline
\end{tabular}

Table 2: Physical properties of the hybrid fuels, pure constituents and diesel

\begin{tabular}{|c|c|c|c|c|}
\hline Fuel type & $\begin{array}{l}\text { Relative density } \\
\text { at } 26^{\circ} \mathrm{C}\end{array}$ & $\begin{array}{l}\text { Kinematic viscosity } \\
\text { at } 26^{\circ} \mathrm{C}(\mathrm{cSt})\end{array}$ & $\begin{array}{l}\text { Kinematic viscosity } \\
\text { at } 20^{\circ} \mathrm{C}(\mathrm{cSt})\end{array}$ & $\begin{array}{l}\text { Gross calorific } \\
\text { value }\left(\mathrm{kJ} \mathrm{g}^{-1}\right)\end{array}$ \\
\hline Diesel & $0.8365 \pm 0.0002$ & $6.07 \pm 0.04$ & $7.28 \pm 0.03$ & $45.1 \pm 0.8$ \\
\hline Aqueous ethanol $(95 \%)$ & $0.7985 \pm 0.0003$ & $1.97 \pm 0.02$ & $2.17 \pm 0.07$ & $27.3 \pm 0.4$ \\
\hline Octan-1-ol & $0.8200 \pm 0.0006$ & $8.67 \pm 0.14$ & $10.24 \pm 0.04$ & $44.0 \pm 0.4$ \\
\hline Crude coconut oil & $0.9159 \pm 0.0007$ & $43.77 \pm 0.92$ & Freezes & $38.7 \pm 0.4$ \\
\hline Virgin coconut oil & $0.9174 \pm 0.0004$ & $43.05 \pm 0.73$ & Freezes & $38.8 \pm 0.4$ \\
\hline \multicolumn{5}{|l|}{ Hybrid fuels } \\
\hline $\mathrm{HF} 1[85(\mathrm{CCO}), 9,6]$ & $0.9021 \pm 0.0006$ & $21.86 \pm 0.23$ & $25.51 \pm 0.06$ & $37.2 \pm 0.6$ \\
\hline $\mathrm{HF} 2[67(\mathrm{CCO}), 17,16]$ & $0.8808 \pm 0.0005$ & $12.81 \pm 0.23$ & $15.60 \pm 0.02$ & $37.7 \pm 0.9$ \\
\hline HF3 [50(CCO), 21, 29] & $0.8640 \pm 0.0009$ & $9.02 \pm 0.03$ & $10.77 \pm 0.03$ & $37.1 \pm 0.5$ \\
\hline HF4 [86(VCO), 9, 5] & $0.9019 \pm 0.0002$ & $21.56 \pm 0.19$ & $25.35 \pm 0.03$ & $36.4 \pm 0.4$ \\
\hline HF5 [67(VCO), 17, 16] & $0.8820 \pm 0.0005$ & $12.82 \pm 0.13$ & $15.55 \pm 0.03$ & $38.4 \pm 0.2$ \\
\hline HF6 [50(VCO), 22, 28] & $0.8635 \pm 0.0005$ & $8.88 \pm 0.15$ & $10.64 \pm 0.02$ & $38.6 \pm 0.3$ \\
\hline
\end{tabular}


When the engine reached the operating temperature, load was adjusted using the electrical apparatus (light bulbs). The engine was tested at various loads $(0,30,56$ and $86 \%$ ) of the maximum electrical output of the generator. The load was monitored using a power meter connected in series to the load bank. The fuel consumption was measured using the constant volume time method wherein the fuel flow rate was measured from the volume change in the measuring cylinder.

A PG-250 model, Horiba portable gas analyzer was used for measuring the exhaust emissions by inserting its probe into the exhaust pipe of the engine. The analyzer measured the concentration of $\mathrm{NO}(\mathrm{ppm}), \mathrm{SO}_{2}$ (ppm), $\mathrm{CO}$ (ppm), $\mathrm{CO}_{2}$ (vol. \%) and $\mathrm{O}_{2}$ (vol. \%).

\section{RESULTS AND DISCUSSION}

The ternary phase diagrams, represented in Fig. 1, shows the miscibility curves for the hybrid fuels at $26^{\circ} \mathrm{C}$. The formulations above the miscibility curve exists as one visible phase in the form of thermodynamically stable microemulsions, while those below the curves were unstable and have two visible distinct phases.

As seen in Fig. 1, only $8 \%$ of ethanol can be blended with CCO or VCO without the help of a surfactant. This is due to the high polarity of ethanol. Consequently coconut oil, which is a non-polar molecule, is not compatible with $95 \%$ ethanol. The use of surfactants therefore became necessary after the ethanol concentration exceeds $8 \%$.

Properties of the hybrid fuels: The densities, viscosities and gross calorific values of the hybrid fuels as well as the pure constituents and diesel are given in Table 2.

The densities of the hybrid fuels decrease with the incorporation of ethanol and octan-1-ol. Both the alcohols have a lower density compared to the oils and as a result incorporation of these decreases the density of the hybrid fuels.

The same trend is observed for the viscosities which are significantly lowered through the addition of the alcohols. The hybrid fuels containing either $\mathrm{CCO}$ or VCO but with same percentage of ethanol and octan-1ol have similar viscosities. The hybrid fuel HF3 and HF6 have viscosities of 9.02 and $8.88 \mathrm{cSt}$, which are pretty close to that of diesel. The formation of the hybrid fuels has the added advantage of suppressing the freezing points, thus extending the temperature range over which the fuel can be used. CCO and VCO freezes at temperatures below $24^{\circ} \mathrm{C}$ posing challenges in cooler climates, but the hybrid fuels freezing point is suppressed due to the low freezing point of its constituents, ethanol and octanol.

The Gross Calorific Values (GCV) of $\mathrm{CCO}$ and VCO are similar but $14 \%$ lower than that of diesel. As the volume of ethanol increases in the hybrid fuels, the GCV decrease due to the low GCV of ethanol. However, octan-1-ol has a high GCV $\left(43.98 \mathrm{~kJ} \mathrm{~g}^{-1}\right.$ compared to $27.31 \mathrm{~kJ} \mathrm{~g}^{-1}$ for ethanol) and as its concentration increases the GCV increases as well. The GCV of the hybrid fuels is approximately $15 \%$ lower than diesel.

Fuel consumption: The Specific Fuel Consumption (SFC) (i.e., the ratio of fuel mass flow of an engine to its output power) of the engine for the six hybrid fuels, CCO, VCO and diesel are shown in Fig. 2 and 3.

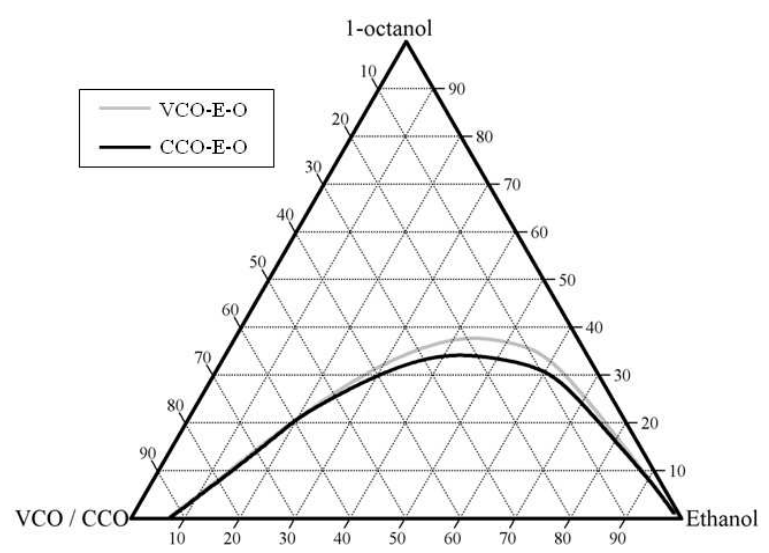

Fig. 1: Ternary phase diagram showing the phase behaviour of virgin coconut oil/crude coconut oil-ethanol-octan-1-ol system at $26^{\circ} \mathrm{C}$

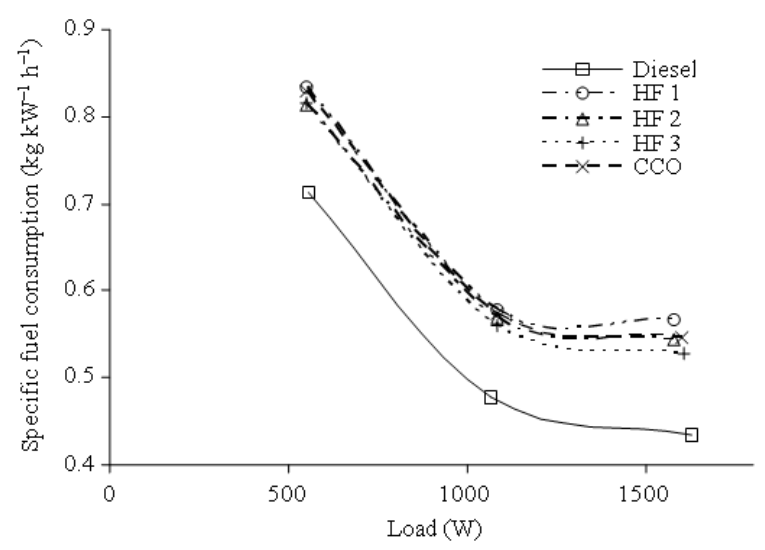

Fig. 2: Specific fuel consumption for crude coconut oil based hybrid fuels and diesel 
Am. J. Environ. Sci., 6 (1): 71-77, 2010

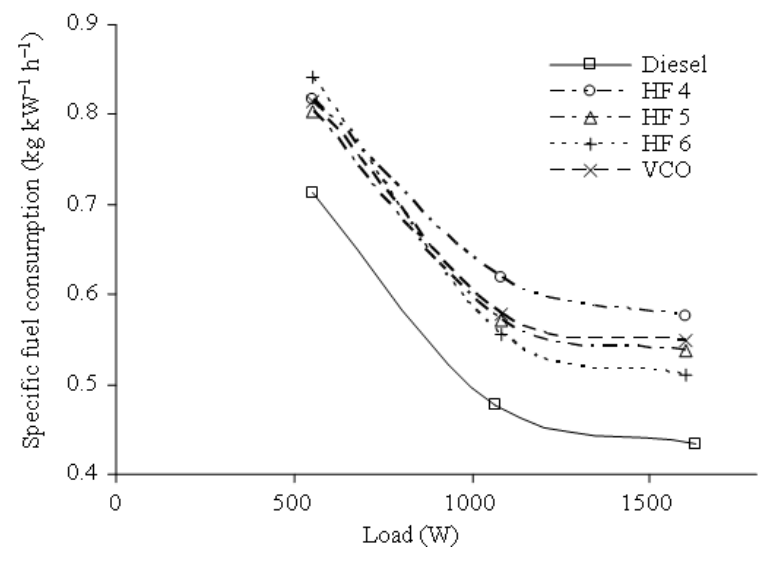

Fig. 3: Specific fuel consumption for virgin coconut oil based hybrid fuels and diesel

It is evident from the Fig. 2 and 3 that the SFC decreases with increase in the load. The SFC compensates for the power output and thus as the power output increases the SFC decreases.

Figure 2 and 3 also indicate that the SFC of the hybrid fuels is higher compared to diesel. This is consistent with the fact that the SFC increased with decreasing GCV as to supply the same power, fuels having lower GCV are consumed at a higher rate. Hybrid fuels have lower gross calorific values as compared to that of diesel, so their SFC curves lie above that of the diesel curve and hybrid fuel having the lowest GCV had the highest SFC. The trend was similar for both types of coconut oils. The SFC increases with increasing ethanol in the hybrid fuels. This is due to the relationship among volumetric fuel injection system, the fuel density, viscosity and GCV. As a result, higher volumes of the hybrid fuels are needed to produce the same amount of energy due to its higher density and lower GCV compared to diesel.

Engine efficiency: Engine efficiency relates the useful work output to the energy contained in the fuel. In Fig. 4 and 5, engine efficiency of diesel, coconut oils and the hybrid fuels has been plotted. There is a steady increase in the efficiency as the load increases for all the fuel types. The engine efficiency is the lowest for both type of coconut oils which can be attributed to their high viscosity and density and poor mixture formation as a result of the low volatility. The efficiencies of the hybrid fuels are very close to that of diesel. The small differences among these curves may be accounted for in terms of differences in fuel properties such as viscosity and density.

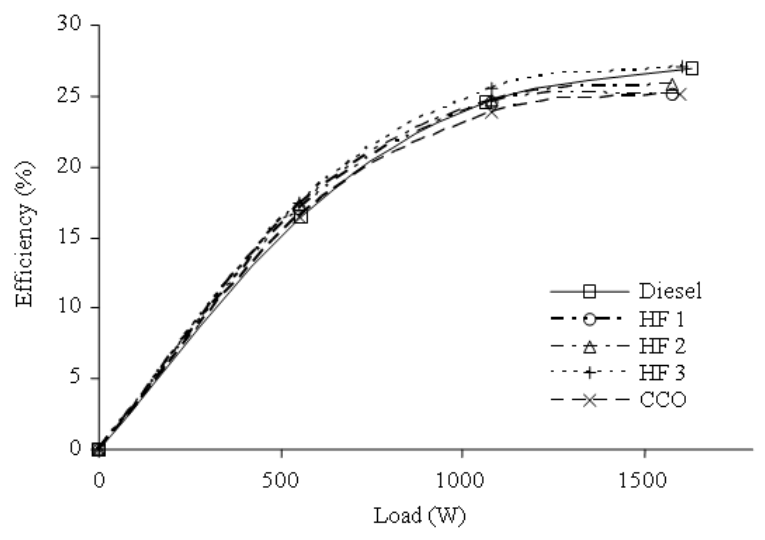

Fig. 4: Engine efficiency for crude coconut oil based hybrid fuels and diesel

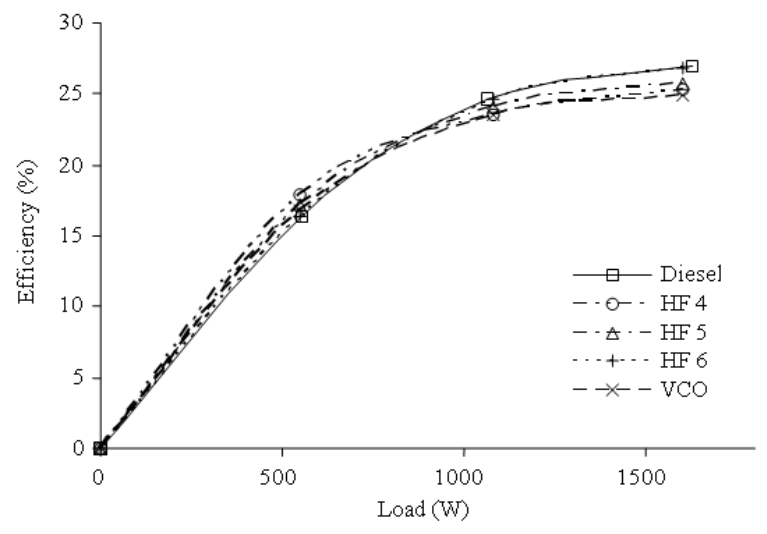

Fig. 5: Engine efficiency for virgin coconut oil based hybrid fuels and diesel

Lower engine efficiency of both the coconut oils can be explained using the following arguments. Firstly, the quality of the spray with hybrid fuels is improved since the boiling point of ethanol is lower than that of diesel. It therefore has higher reaction activity in the fuel-rich zone due to the oxygenate of ethanol. In addition, heat losses decrease in the cylinder due to lower flame temperature of ethanol than that of diesel (Kim and Choi, 2008).

As discussed earlier, hybrid fuels have higher SFC due to lower GCV. However, in spite of the large quantity of injected fuel, hybrid fuels had efficiencies similar to diesel. This result indicates that fuels containing ethanol have higher reaction activity in the fuel rich zone due to oxygenate of ethanol in high load conditions (Kim and Choi, 2008).

Emission characteristics: The effect of load on NO emissions for coconut oil, diesel and the hybrid fuels is shown in Fig. 6 and 7. NO emissions from the hybrid fuels were considerably lower than that from diesel. 
Am. J. Environ. Sci., 6 (1): 71-77, 2010

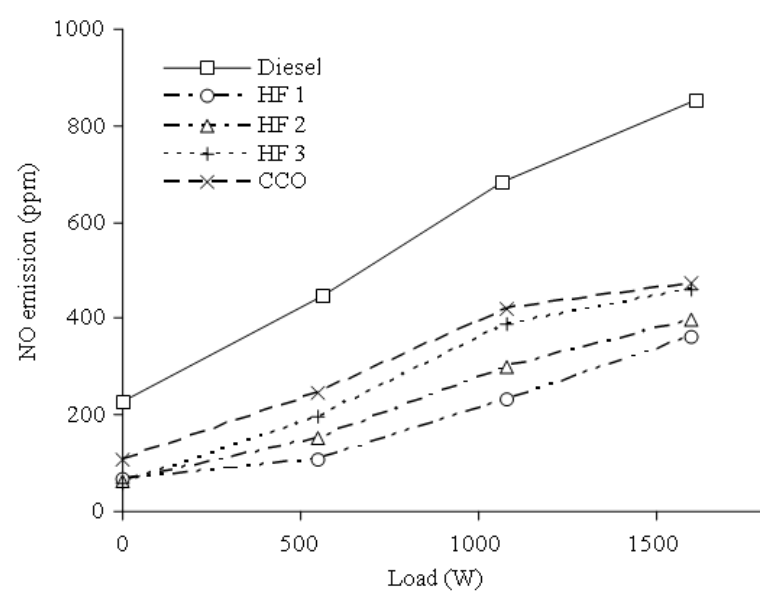

Fig. 6: NO emissions from crude coconut-oil based hybrid fuels compared to diesel

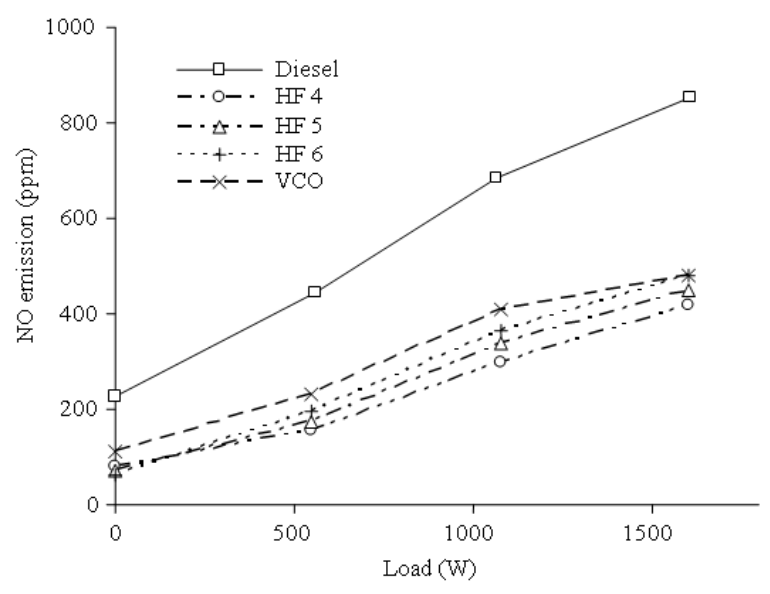

Fig. 7: NO emissions from virgin coconut-oil based hybrid fuels compared to diesel

This can be explained on the basis of lower heat release rates of the hybrid fuels during premixed combustion phase, resulting in lower peak temperatures. As NO formation strongly depends on peak temperature, lower emission rates from hybrid fuels are expected. It has been reported that 5\% water present in the ethanol serves as a heat sink, thereby lowering combustion temperatures and reducing $\mathrm{NO}_{\mathrm{x}}$ emissions (Wenzel and Steinmann, 1978).

$\mathrm{CO}$ emissions at different loads for diesel and the hybrid fuels of CCO and VCO are shown in Fig. 8 and 9. $\mathrm{CO}$ is produced when engine is being operated on high fuel to air ratio and there is insufficient oxygen for complete combustion (Kalam and Masjuki, 2004). The CO emission levels of the CCO and VCO hybrid fuels are greater than diesel and decrease as concentration of ethanol in the hybrid fuel increases.

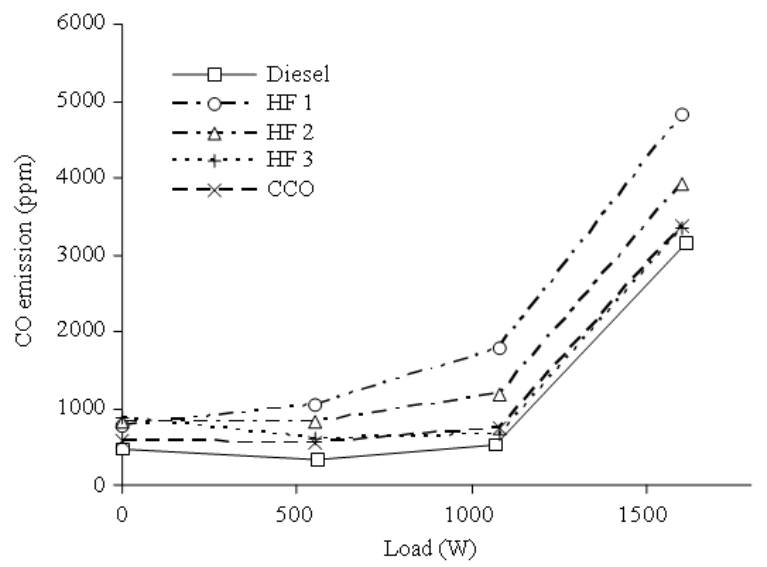

Fig. 8: CO emissions from crude coconut-oil based hybrid fuels compared to diesel

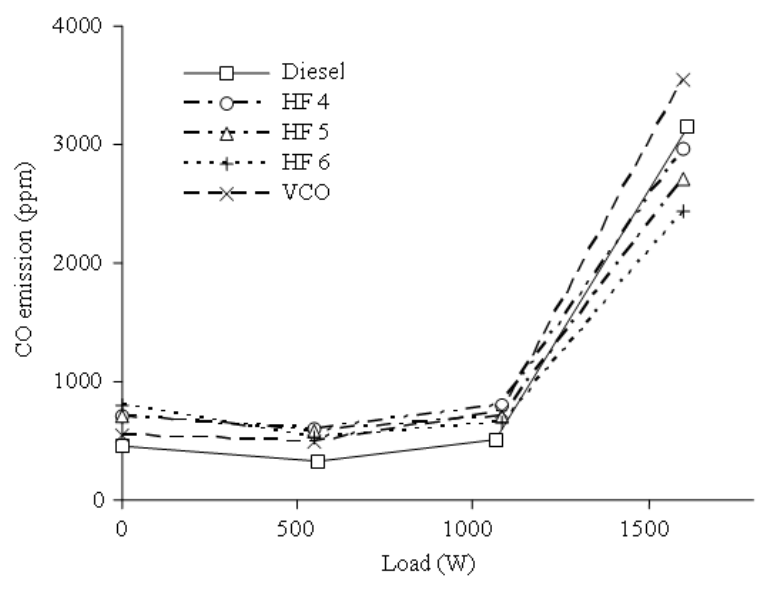

Fig. 9: CO emissions from virgin coconut-oil based hybrid fuels compared to diesel

An explanation lies in the fact that the higher percentage of ethanol in the hybrid fuels means availability of more fuel bound oxygen leading to complete combustion and thus a reduction in the $\mathrm{CO}$ emission levels.

The high CO emission levels of the hybrid fuels compared to diesel may also be explained by an increased premixed combustion due to a long ignition delay by the high latent heat of vaporization of ethanol. There is also a possibility of the formation of intermediate components in the fuel-rich zone of the hybrid fuels.

The $\mathrm{SO}_{2}$ emission characteristics for diesel and the hybrid fuels are shown in Fig. 10 and 11. $\mathrm{SO}_{2}$ emission for the hybrid fuels are reduced by as much as $64 \%$ for CCO based hybrid fuels and 70\% for VCO based hybrid fuels compared to diesel at the maximum load condition. 


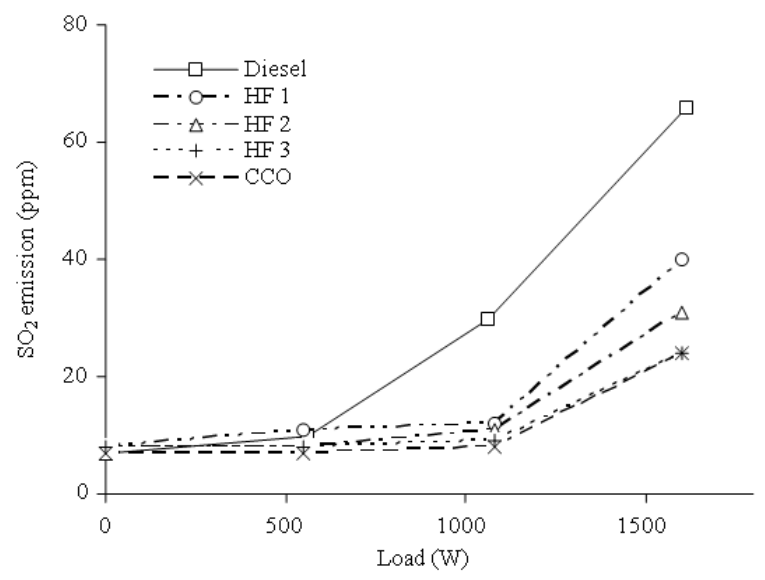

Fig. 10: $\mathrm{SO}_{2}$ emissions from crude coconut-oil based hybrid fuels compared to diesel

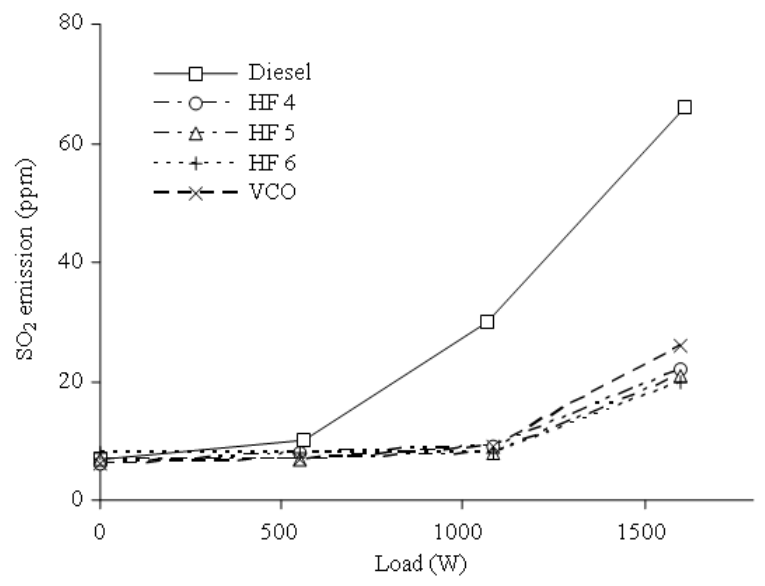

Fig. 11: $\mathrm{SO}_{2}$ emissions from virgin coconut-oil based hybrid fuels compared to diesel

The variation of $\mathrm{CO}_{2}$ emissions with load is shown in Fig. 12 and 13. $\mathrm{CO}_{2}$ is a by-product of complete combustion. It can be used as an indicator for determining the efficiency of combustion occurring. The $\mathrm{CO}_{2}$ emission levels of the $\mathrm{CCO}$ and VCO hybrid fuels are lower than diesel which can be attributed to the incomplete combustion. As concentration of ethanol in the hybrid fuel increase, there is a slight decrease in the $\mathrm{CO}_{2}$ emission levels. An explanation lies in the fact that for hybrid fuels contain less number of carbon atoms per unit mass of the fuel as compared to diesel.

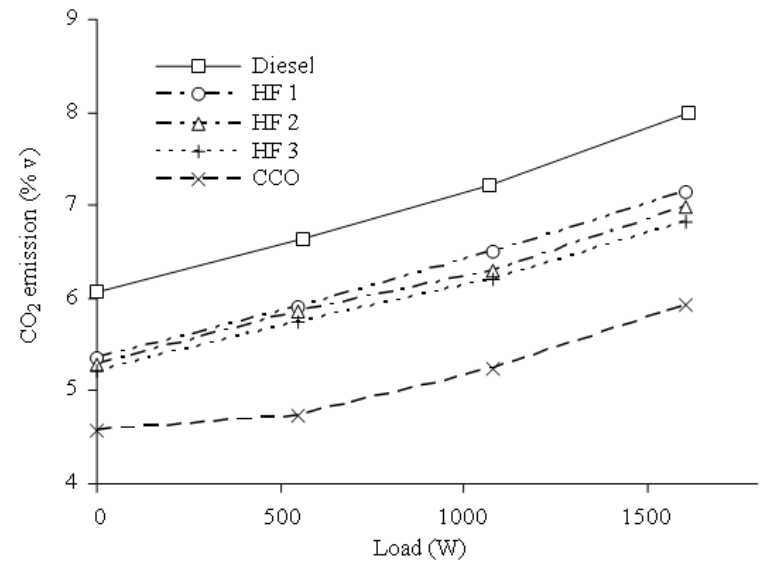

Fig. 12: $\mathrm{CO}_{2}$ emissions from crude coconut-oil based hybrid fuels compared to diesel

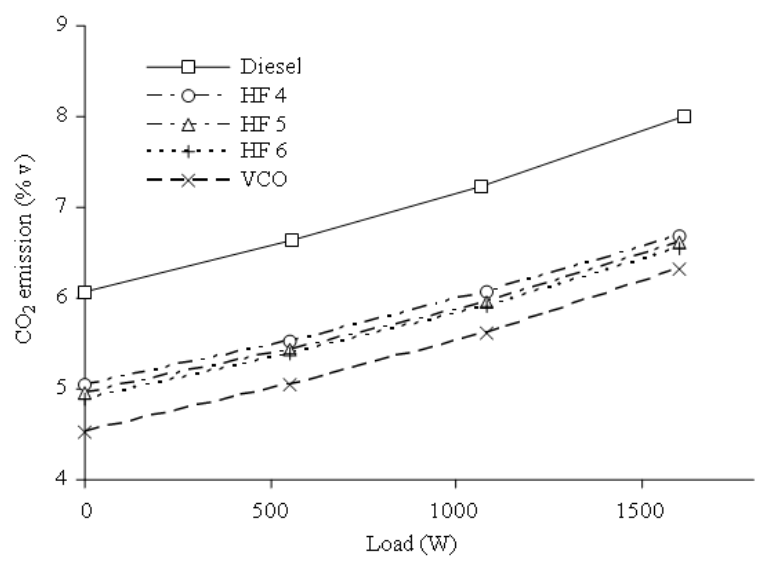

Fig. 13: $\mathrm{CO}_{2}$ emissions from virgin coconut-oil based hybrid fuels compared to diesel

\section{CONCLUSION}

In this study, the preparation, characterisation, engine performance and emission characteristics of coconut oil based hybrid fuels were investigated. The following conclusions can be drawn:

- Octan-1-ol can be used as an effective surfactant to prepare a stable and homogenous microemulsion of coconut oil and aqueous ethanol of $95 \%$ purity

- The viscosity of pure coconut oil can be reduced to close to that of diesel using the microemulsification technique

- The engine efficiency of the hybrid fuels is similar compared to diesel and improves as the viscosity of the fuel decreases 
- The specific fuel consumption of the hybrid fuels are higher compared to diesel due to the lower gross calorific value of the hybrid fuels

- The emissions levels $\left(\mathrm{NO}, \mathrm{SO}_{2}\right.$ and $\mathrm{CO}_{2}$ ) of the hybrid fuels are lower compared to diesel, but an increase in $\mathrm{CO}$ emission levels is observed

- The hybrid fuel can be used as a fuel without any modification in a direct injection diesel engine

\section{ACKNOWLEDGMENT}

This study was funded by the Secretariat of the Pacific Islands Applied Geoscience Commission and we are grateful for its financial contribution.

\section{REFERENCES}

Demirbas, A., 2006. Biodiesel production via noncatalytic SCF method and biodiesel fuel characteristics. Energy Conver. Manage., 47: 2271-2282. DOI: 10.1016/j.enconman.2005.11.019

Demirbas, A., 2008 Biodiesel: A Realistic Fuel Alternative for Diesel Engines. 1st Edn., SpringerVerlag, London, ISBN: 978846289941, pp: 14-67.

Kalam, M.A. and H.H. Masjuki, 2004. Emissions and deposit characteristics of a small diesel engine when operated on preheated crude palm oil. Biomass Bioenergy, 27: 289-297. DOI: 10.1016/j.biombioe.2004.01.009

Kim, H. and B. Choi, 2008. Effect of ethanol-diesel blend fuels on emission and particle size distribution in a common-rail direct injection diesel engine with a warm-up catalytic converter. Renew. Energy, $\quad 33$ : 2222-2228. DOI: 10.1016/j.renene.2008.01.002
Machacon, H.T.C., Y. Matsumoto, C. Ohkawara, S. Shiga, T. Karasawa and H. Nakamura, 2001. The effect of coconut oil and diesel fuel blends on diesel engine performance and exhaust emissions. Soc. Automot. Eng. Jap., 22: 349-355. DOI: 10.1016/S03894304(01)00111-4

Nwafor, O.M.I., 2004. Emission characteristics of diesel engine running on vegetable oil with elevated fuel inlet temperature. Biomass Bioenergy, 27: 507-511. DOI: 10.1016/j.biombioe.2004.02.004

Pryde, E.H., 1984. Vegetable oils as fuel alternativessymposium overview. J. Am. Oil Chem. Soc., 61: 1609-1610. DOI: 10.1007/BF02541644

Puhan, S. and G. Nagarajan, 2008. $\mathrm{NO}_{\mathrm{x}}$ reduction in a DI diesel engine using biodiesel as a renewable fuel. Int. J. Sustain. Energy, 27: 143-154. DOI: 10.1080/14786450802316644

Rakopoulos, C.D., K.A. Antonopoulo, D.C. Rakopoulos, D.T. Hountalas and E.G. Giakoumis, 2006. Comparative performance and emission study of a direct injection diesel engine using blends of diesel fuel with vegetable oils or bio-diesels of various origins. Energy Conver. Manage., 47: 3272-3287. DOI: 10.1016/j.enconman.2006.01.006

Srivastava, A. and R. Prasad, 2000. Triglycerides-based diesel fuels. Renew. Sustain. Energy Rev., 4: 111-133. DOI: 10.1016/S1364-0321(99)00013-1

Wenzel, E.C. and H.W. Steinmann, 1978. Clear and stable liquid fuel compositions for internal combustion engines. US Patent 4083698. http://www.freepatentsonline.com/4083698.html 